\title{
Last Observation Carried Forward Imputation Technique
}

National Cancer Institute

\section{Source}

National Cancer Institute. Last Observation Carried Forward Imputation Technique. NCI

Thesaurus. Code C81198.

The substitution of missing data with the most recent data collected that is not missing. 